\title{
Motives for romantic relationships and the risk of heavy alcohol use, regular smoking and cannabis use during adolescence and early adulthood: A longitudinal study ${ }^{*}$
}

\author{
Wenbin Liang", Tanya Chikritzhs \\ National Drug Research Institute, Curtin University, Perth, Australia \\ Email: ${ }^{\text {w.liang@curtin.edu.au }}$
}

Received 25 March 2013; revised 26 April 2013; accepted 4 May 2013

Copyright (C 2013 Wenbin Liang, Tanya Chikritzhs. This is an open access article distributed under the Creative Commons Attribution License, which permits unrestricted use, distribution, and reproduction in any medium, provided the original work is properly cited.

\begin{abstract}
Background: Engaging in sexual activities at a younger age is associated with higher risk of substance misuse among adolescents. It could be hypothesized that substance misuse and certain romantic relationship related behaviors may be influenced by similar hormone and other inner physiological factors that are affected by related motives. This study investigated the association between motives for romantic relationships and the risk of heavy alcohol use, regular smoking and cannabis use from adolescence through to early adulthood. Method: A population-based longitudinal study using data collected from Wave I and Wave III of the National Longitudinal Study of Adolescent Health. Characteristics of romantic relationship ideals (as the proxy of motives) measured in Wave I (mean age: 16 yrs) were applied to predict substance use indicated at Wave III (mean age: 22 yrs) using multivariate analyses. Results: Adolescents who included sexual activities as part of their romantic relationship ideals were at significantly higher risk of cannabis use among males and heavy alcohol use among females. Romantic ideals that included, gift giving (female) or receiving (male), declaration of love (male), marriage (male) and becoming pregnant (female) were associated with reduced risk of one or more types of substance use. Conclusion: In adolescence, sexual motives for romantic relationships were associated with higher risk of substance use and misuse, while motives related to intimacy and commitment in romantic relationships were associated with lower risk.
\end{abstract}

Keywords: Motives; Romantic Relationship; Alcohol; Tobacco; Cannabis; Longitudinal Study

\footnotetext{
*Competing Interests: None.

${ }^{\#}$ Corresponding author.
}

\section{INTRODUCTION}

Heavy alcohol use, tobacco smoking and cannabis use are common risk factors for mental disorders and chronic physical conditions in adolescence and young adults [1-3]. It has been suggested that engaging in sexual activities is associated with substance misuse among adolescents and young adults [4,5]. There is also some evidence to suggest that dissolution of romantic relationships may be linked to heavy drinking, cannabis use, and tobacco smoking among young adults [6]. The causal mechanism behind the observed association between romantic relationship and substance use in adolescence and young adulthood is not well understood. There is some evidence suggesting that the same sets of biopsychosocial factors may underpin motives to engaging in romantic relationships and tendency towards substance use. For example, it has been observed that sexual activities within romantic relationships generate pleasurable feelings and reward through similar neurological pathways as drug use [7-9]. The arrival of puberty leads to an upsurge in romantic interest and sexual motivation, while increases in sex hormones during puberty may increase the likelihood of risk taking behaviors such as drug use [10, 11]. On the other hand, intelligence appears to be negatively associated with engaging in sexual activity, kissing, or substance use during late childhood and adolescence [12-14]. Hormones and other inner physiological factors can influence behaviors through generating motives. Children and adolescents with certain types of motives for seeking or engaging in romantic relationships may be more or less likely to use substances. An individual's inner motives related to romantic relationships could be reflected by personal ideals about romantic relationships $[15,16]$. In this study we measured the association between romantic relationships ideals (as the proxy of motives) and the risk of heavy alcohol use, regular smoking 
and cannabis use from adolescence through to early adulthood.

\section{METHOD}

This study used data collected from the National Longitudinal Study of Adolescent Health (Add Health). Details of the Add Health study have been described in detail previously [17]. Briefly, Add Health is a longitudinal study with a representative sample of adolescents in grade 7 - 12 at baseline. Participants were initially recruited in 1994-1995 (Wave I), then were followed up in 1996 (Wave II), in 2001-2002 (Wave III), and in 20072008 (Wave IV). A combination of self-administrated questionnaires and interviews were employed to collect social, psychological and health information, including demographics, risk behaviors, health status and family composition. In addition, the Wave I survey included a face-to-face interview with one parent (preferably the mother) of each participant to provide further information on the adolescent and other family members, including health problems and lifestyles. 15,170 participants were interviewed in both of the Wave I and Wave III surveys. The original dataset was not available to the public, but a random sample was drawn from the original core dataset to create a public-use dataset which has been made freely available to the public. This study used the public-use data of the Add Health study.

In the Wave I survey, respondents were given a set of 17 cards, each describing something that might happen in the course of a romantic relationship. Contents of the 17 cards are shown in Table 1. Each participant was asked to imagine their ideal romantic relationship in the next year and to return any card(s) which described things that would not happen in this ideal romantic relationship [18]. In this study, contents of cards kept by a participant were considered as preference of their ideal relationship. Data on substance use patterns collected in Wave III were used to: 1) measure frequency of heavy alcohol use in the last 12 months among drinkers; 2) to determine onset of regular smoking; and 3) determine onset of cannabis use.

In relation to alcohol use, participants were asked whether they had drunk alcohol in the past 12 months. If they responded "yes" then they were also asked the following question: "During the past 12 months, on how many days have you been drunk or very high on alcohol?” Response options were: none, 1 or 2 days in past 12 months, once a month or less, 2 or 3 days a month, 1 or 2 days a week, 3 - 5 days a week and every day/almost every day. Participants who did not consume alcohol in the past 12 months were excluded from further analysis. Onset of regular smoking was defined as having smoked at least one cigarette every day for 30 days during any period before Wave III among participants who had never smoked regularly at Wave I (i.e. onset occurred be- tween Wave I and Wave III). Onset of cannabis use was defined as having ever used cannabis before Wave III among participants who had never used cannabis at Wave I (i.e. onset occurred between Wave I and Wave III).

\section{Data Analysis}

Ordered logistic regression was used to predict the likelihood of heavy alcohol use using elements of ideal relationships and potential confounding factors: gender, age, race, total number of sex (vaginal intercourse) partners so far (at Wave III), sexuality: $100 \%$ heterosexual or not (at wave III), the importance of religion (at Wave I), whether living in a single parent family (at Wave I), highest level of parents' education (at Wave I), whether ever been adopted (at wave III), urbanity and median income of residential location at Wave I. Poisson regression with robust estimation of variance was employed to investigate whether characteristics of a model describing the "ideal relationship" were associated with the onset of regular tobacco smoking and cannabis use while controlling for the same potential confounding factors used in the ordered logistic regression model. For the three models, backward stepwise procedure with variable retention set at $p<0.1$ significance level to select characteristics of an ideal romantic relationship that associated with sub-

Table 1. Participant response options for ideal romantic relationship [18].

\footnotetext{
A. We would go out together in a group.

B. I would meet my partner's parents.

C. I would tell other people that we were a couple.

D. I would see less of my other friends so I could spend more time with my partner.

E. We would go out together alone.

F. We would hold hands.

G. I would give my partner a present.

H. My partner would give me a present.

I. I would tell my partner that I loved him or her.

J. My partner would tell me that he or she loved me.

K. We would think of ourselves as a couple.

L. We would talk about contraception or sexually transmitted diseases.

M. We would kiss.

N. We would touch each other under our clothing or with no clothes on.

O. We would have sex.

P. My partner or I would get pregnant.

Q. We would get married.
} 
stance use. All potential confounding variables were forced to remain in the models.

\section{RESULTS}

The public-use data had a total sample of 4882 participants who were interviewed in both waves and $46 \%$ were male. The mean age for males was 16.0 years at Wave I and 22.4 years at Wave III. For females the mean age was 15.9 years at Wave I and 22.2 years by Wave III.

A total of 1598 males and 1973 females who reported having never used cannabis at Wave I, were successfully followed-up at Wave III. Among these participants, 78\%

Table 2. Sexual activity, romantic relationship ideals and onset of cannabis use ${ }^{1}$.

\begin{tabular}{|c|c|c|c|}
\hline Male & IRR & $95 \%$ & $\mathrm{CI}$ \\
\hline \multicolumn{4}{|l|}{ Confounders } \\
\hline $\begin{array}{l}\text { Number of sex (vaginal intercourse) partners: } \\
\text { none }\end{array}$ & 1.00 & & \\
\hline 1 & 1.46 & 1.03 & 2.07 \\
\hline $2-3$ & 2.16 & 1.58 & 2.95 \\
\hline $4-7$ & 2.57 & 1.90 & 3.49 \\
\hline $8+$ & 2.72 & 1.99 & 3.71 \\
\hline almost or $100 \%$ homosexual & 2.28 & 1.30 & 4.02 \\
\hline \multicolumn{4}{|l|}{ Sexuality, $100 \%$ heterosexual (straight) } \\
\hline Yes & 1.00 & & \\
\hline No & 1.02 & 0.75 & 1.40 \\
\hline \multicolumn{4}{|l|}{ Romantic relationship ideals ${ }^{*}$} \\
\hline \multicolumn{4}{|l|}{ H. My partner would give me a present } \\
\hline No & 1.00 & & \\
\hline Yes & 0.81 & 0.68 & 0.98 \\
\hline \multicolumn{4}{|c|}{ N. Touch each other under clothing or with no clothes on } \\
\hline No & 1.00 & & \\
\hline Yes & 1.24 & 1.07 & 1.42 \\
\hline \multicolumn{4}{|l|}{ K. We would think of ourselves as a couple } \\
\hline No & 1.00 & & \\
\hline Yes & 1.75 & 1.10 & 2.80 \\
\hline \multicolumn{4}{|l|}{ I. I would tell my partner that I loved him or her } \\
\hline No & 1.00 & & \\
\hline Yes & 0.84 & 0.71 & 0.99 \\
\hline \multicolumn{4}{|l|}{ Female } \\
\hline \multicolumn{4}{|l|}{ Confounders } \\
\hline $\begin{array}{l}\text { Number of sex (vaginal intercourse) partners: } \\
\text { none }\end{array}$ & 1.00 & & \\
\hline 1 & 1.10 & 0.74 & 1.62 \\
\hline $2-3$ & 1.85 & 1.30 & 2.61 \\
\hline $4-7$ & 2.54 & 1.80 & 3.58 \\
\hline $8+$ & 3.52 & 2.50 & 4.96 \\
\hline almost or $100 \%$ homosexual & 1.83 & 0.83 & 4.04 \\
\hline \multicolumn{4}{|l|}{ Sexuality, 100\% heterosexual (straight) } \\
\hline Yes & 1.00 & & \\
\hline No & 1.59 & 1.32 & 1.91 \\
\hline \multicolumn{4}{|l|}{ Romantic relationship ideals ${ }^{*}$} \\
\hline \multicolumn{4}{|c|}{ L. We talk about contraception or sexually transmitted diseases } \\
\hline No & 1.00 & & \\
\hline Yes & 1.20 & 1.02 & 1.41 \\
\hline \multicolumn{4}{|l|}{ G. I would give my partner a present } \\
\hline No & 1.00 & & \\
\hline Yes & 0.78 & 0.63 & 0.98 \\
\hline
\end{tabular}

*Shows all significant $(p<0.05)$ variables selected by backward stepwise procedure and in the model. ${ }^{1}$ Model adjusted for gender, age, race, total number of sex (vaginal intercourse) partners (Wave III), sexuality: 100\% heterosexual or not (Wave III), importance of religion (Wave I), whether living in a single parent family (Wave I), highest level of parents' education (Wave I), whether ever been adopted (Wave III), urbanity and median income of residence location at Wave I. 
Table 3. Sexual activity, romantic relationship ideals and heavy alcohol use (no heavy use in past 12 months as reference group) ${ }^{1}$.

\begin{tabular}{|c|c|c|c|}
\hline Male & OR & $95 \%$ & $\mathrm{CI}$ \\
\hline \multicolumn{4}{|l|}{ Confounders } \\
\hline $\begin{array}{l}\text { Number of sex (vaginal intercourse) partners } \\
\text { none }\end{array}$ & 1.00 & & \\
\hline 1 & 1.14 & 0.74 & 1.75 \\
\hline $2-3$ & 1.42 & 0.96 & 2.11 \\
\hline $4-7$ & 1.91 & 1.27 & 2.87 \\
\hline $8^{+}$ & 3.07 & 2.03 & 4.65 \\
\hline almost or $100 \%$ homosexual & 2.70 & 0.73 & 9.95 \\
\hline \multicolumn{4}{|l|}{ Sexuality, $100 \%$ heterosexual (straight) } \\
\hline Yes & 1.00 & & \\
\hline No & 1.05 & 0.55 & 1.99 \\
\hline \multicolumn{4}{|l|}{ Romantic relationship ideals ${ }^{*}$} \\
\hline \multicolumn{4}{|l|}{ A. We would go out together in a group } \\
\hline No & 1.00 & & \\
\hline Yes & 1.52 & 1.06 & 2.17 \\
\hline \multicolumn{4}{|l|}{ Q. We would get married } \\
\hline No & 1.00 & & \\
\hline Yes & 0.69 & 0.51 & 0.93 \\
\hline \multicolumn{4}{|c|}{$\mathrm{N}$. Touch each other under our clothing or with no clothes on } \\
\hline No & 1.00 & & \\
\hline Yes & 1.89 & 1.44 & 2.49 \\
\hline
\end{tabular}

Confounders

Number of sex (vaginal intercourse) partners none

1

$2-3$

0.92

0.59

1.43

$4-7$

1.98

1.28

3.06

$4-7$

2.26

1.45

3.52

$8^{+}$

3.65

2.33

5.72

almost or $100 \%$ homosexual

9.05

2.43

33.75

Sexuality, 100\% heterosexual (straight)

Yes

1.00

No

Romantic relationship ideals*

$\mathrm{N}$. Touch each other under our clothing or with no clothes on

No

1.00

Yes

P. My partner or I would get pregnant

No

1.00

Yes

0.53

0.36

0.78

*Shows all significant $(p<0.05)$ variables selected by backward stepwise procedure and in the model. ${ }^{1}$ Model adjusted for gender, age, race, total number of sex (vaginal intercourse) partners (Wave III), sexuality: 100\% heterosexual or not (Wave III), importance of religion (Wave I), whether living in a single parent family (Wave I), highest level of parents' education (Wave I), whether ever been adopted (Wave III), urbanity and median income of residence location at Wave I. 
Table 4. Sexual activity, romantic relationship ideals and onset of regular smoking ${ }^{1}$.

\begin{tabular}{|c|c|c|c|}
\hline Male & IRR & $95 \%$ & CI \\
\hline \multicolumn{4}{|l|}{ Confounders } \\
\hline $\begin{array}{l}\text { Number of sex (vaginal intercourse) partners } \\
\text { none }\end{array}$ & 1.00 & & \\
\hline 1 & 1.92 & 1.22 & 3.01 \\
\hline $2-3$ & 2.37 & 1.52 & 3.69 \\
\hline $4-7$ & 3.32 & 2.18 & 5.04 \\
\hline $8^{+}$ & 3.39 & 2.21 & 5.20 \\
\hline almost or $100 \%$ homosexual & 2.82 & 1.56 & 5.09 \\
\hline \multicolumn{4}{|l|}{ Sexuality, $100 \%$ heterosexual (straight) } \\
\hline Yes & 1.00 & & \\
\hline No & 1.29 & 0.97 & 1.71 \\
\hline \multicolumn{4}{|l|}{ Romantic relationship ideals ${ }^{*}$} \\
\hline \multicolumn{4}{|l|}{ M. We would kiss } \\
\hline No & 1.00 & & \\
\hline Yes & 1.62 & 1.07 & 2.44 \\
\hline \multicolumn{4}{|l|}{ C. I would tell other people that we were a couple } \\
\hline No & 1.00 & & \\
\hline Yes & 0.74 & 0.60 & 0.93 \\
\hline \multicolumn{4}{|l|}{ E. We would go out together alone } \\
\hline No & 1.00 & & \\
\hline Yes & 0.74 & 0.57 & 0.96 \\
\hline
\end{tabular}

Confounders

Number of sex (vaginal intercourse) partners: none

$8+$

almost or $100 \%$ homosexual

Sexuality, 100\% heterosexual (straight)

$$
\text { Yes }
$$

No

Romantic relationship ideals*

E. We would go out together alone

$\begin{array}{ll}\text { No } & 1.00 \\ \text { Yes } & 0.73\end{array}$

C. I would tell other people that we were a couple

$$
\text { No }
$$

$$
\text { Yes }
$$

"Shows all significant $(p<0.05)$ variables selected by backward stepwise procedure and in the model. ${ }^{1}$ Model adjusted for gender, age, race, total number of sex (vaginal intercourse) partners (Wave III), sexuality: 100\% heterosexual or not (Wave III), importance of religion (Wave I), whether living in a single parent family (Wave I), highest level of parents' education (Wave I), whether ever been adopted (Wave III), urbanity and median income of residence location at Wave I. 
of males (1257) and 77\% of females (1529) provided complete information for all questions required for the analysis of cannabis use onset. Confounding variables related to sexual activity and elements of ideal romantic relationships retained in the model are shown in Table 2. Overall, 4 and 2 elements of ideal romantic relationships were significantly associated with onset of cannabis use in young males and females respectively.

There were 1640 males and 1796 females who reported having consumed alcohol during the past 12 months at Wave III. Some $79 \%$ of males (1293) and $80 \%$ of females (1428) provided complete information for all questions required for the analysis of heavy alcohol use. Results are shown in Table 3. For males, three elements predicted heavy alcohol use, and for females two elements were predictive.

There were 1785 males and 2116 females who reported having never smoked on a regular basis at Wave I, and who were successfully followed-up at Wave III. Of these participants, $76 \%$ of males (1363) and 78\% of females (1644) provided complete information for all questions required for the analysis of onset of regular smoking. Results have been shown in Table 4. Three and two elements of ideal romantic relationships were significantly associated with onset of regular smoking among young males and females respectively.

For all substances, number of sex partners was predictive, with fewer sex partners (vaginal intercourse) associated with lower likelihoods of heavy alcohol use or tobacco and cannabis onset.

\section{DISCUSSION}

Having had a larger number of sex partners was associated with significantly higher risk of heavy drinking, regular smoking and onset of cannabis use. This is consistent with results from previous studies $[4,19]$, and suggests that engaging in sexual activities is positively associated with risk of substance misuse and abuse.

Even after controlling for total number of sex partners, sexuality and other possible confounding factors (e.g. importance of religion), adolescents who included sexual activities (e.g. "We would touch each other under our clothing or with no clothes on") among their romantic relationship ideals had significantly higher risk of cannabis onset in males and heavy alcohol use in females. These findings suggest that adolescents who had sexual motives for a romantic relationship were at higher risk of substance use. From the physiological perspective, it has been suggested that sexual activity and drug use are both reward-driven behaviors and the associated pleasurable feelings are generated through similar neurological pathways [7-9]. There was also some data suggesting that increasing levels of androgens during puberty increased the likelihood of engaging in sexual activity, substance misuse and abuse, especially among males [11, 20].

Nevertheless there were a number of ideal romantic relationship elements which, when preferred by participants, showed protective effects for cannabis onset, heavy alcohol use or onset of regular smoking including: gift giving (female) or receiving (male); declaration of love (male); marriage (male) and becoming pregnant (female). These preferences tend to indicate intimacy and commitment which may be considered important for long-term supportive romantic relationships [16,21-24]. Thus, observations from this study suggest that adolescents who are motivated by the intimacy and commitment of romantic relationships may be at lower risk of substance use. It is also possible that these adolescents may be more likely to engage in long-term and supportive romantic relationships which in turn reduces the risk of substance misuse [25,26].

\section{CONCLUSION}

In adolescence, sexual motives for romantic relationships were associated with higher risk of substance use and misuse, while motives related to intimacy and commitment in romantic relationships were associated with lower risk.

\section{ACKNOWLEDGEMENTS}

This work was supported by the Australian Government Department of Health and Ageing under the National Drug Strategy's funding of the National Drug Research Institute. This research uses data from Add Health, a program project designed by J. Richard Udry, Peter S. Bearman, and Kathleen Mullan Harris, and funded by a grant P01-HD31921 from the Eunice Kennedy Shriver National Institute of Child Health and Human Development, with cooperative funding from 17 other agencies. Special acknowledgment is due to Ronald R. Rindfuss and Barbara Entwisle for assistance in the original design. Persons interested in obtaining data files from Add Health should contact Add Health, Carolina Population Center, 123 W. Franklin Street, Chapel Hill, NC 27516- 2524 (addhealth@unc.edu). No direct support was received from grant P01-HD31921 for this analysis.

\section{REFERENCES}

[1] Johnston, L.D., O’Malley, P.M., Bachman, J.G. and Schulenberg, J.E. (2009) Monitoring the future: National survey results on drug use, 1975-2008. National Institute on Drug Abuse USA.

[2] Palmer, R.H.C., Young, S.E., Hopfer, C.J., Corley, R.P., Stallings, M.C., Crowley, T.J., et al. (2009) Developmental epidemiology of drug use and abuse in adolescence and young adulthood: Evidence of generalized risk. Drug and Alcohol Dependence, 102, 78-87. doi:10.1016/j.drugalcdep.2009.01.012

[3] AIHW (2007) National Drug Strategy Household Survey: Detailed findings. 2008, Australian Institute of Health and 
Welfare, Canberra.

[4] Hallfors, D.D., Waller, M.W., Bauer, D., Ford, C.A. and Halpern, C.T. (2005) Which comes first in adolescencesex and drugs or depression? American Journal of Preventive Medicine, 29, 163-170. doi:10.1016/j.amepre.2005.06.002

[5] Graves, K.L. and Leigh, B.C. (1995) The relationship of substance use to sexual activity among young adults in the United States. Family Planning Perspectives, 27, 1833. doi: $10.2307 / 2135972$

[6] Fleming, C.B., White, H.R., Oesterle, S., Haggerty, K.P. and Catalano, R.F. (2010) Romantic relationship status changes and substance use among 18- to 20-year-olds. Journal of Studies on Alcohol and Drugs, 71, 847-856.

[7] Camí, J. and Farré, M. (2003) Drug addiction. New England Journal of Medicine, 349, 975-986. doi:10.1056/NEJMra023160

[8] Kovacs, G.L., Sarnyai, Z. and Szabo, G. (1998) Oxytocin and addiction: A review. Psychoneuroendocrinology, 23, 945-962. doi:10.1016/S0306-4530(98)00064-X

[9] McGregor, I.S., Callaghan, P.D. and Hunt, G.E. (2008) From ultrasocial to antisocial: A role for oxytocin in the acute reinforcing effects and long-term adverse consequences of drug use? British Journal of Pharmacology, 154, 358-368. doi:10.1038/bjp.2008.132

[10] Steinberg, L. (2005) Cognitive and affective development in adolescence. Trends in Cognitive Sciences, 9, 69-74. doi:10.1016/j.tics.2004.12.005

[11] Sato, S.M., Schulz, K.M., Sisk, C.L. and Wood, R.I. (2008) Adolescents and androgens, receptors and rewards. Hormones and Behavior, 53, 647-658. doi:10.1016/j.yhbeh.2008.01.010

[12] Halpern, C.T., Joyner, K., Udry, J.R. and Suchindran, C. (2000) Smart teens don't have sex (or kiss much either). Journal of Adolescent Health, 26, 213-225. doi:10.1016/S1054-139X(99)00061-0

[13] Trinidad, D.R. and Johnson, C.A. (2002) The association between emotional intelligence and early adolescent tobacco and alcohol use. Personality and Individual Differences, 32, 95-105. doi:10.1016/S0191-8869(01)00008-3

[14] Whelan, R., Conrod, P.J., Poline, J.-B., Lourdusamy, A., Banaschewski, T., Barker, G.J., et al. (2012) Adolescent impulsivity phenotypes characterized by distinct brain networks. Nature Neuroscience, 15, 920-925. doi:10.1038/nn.3092

[15] Fletcher, G.J.O., Simpson, J.A., Thomas, G. and Giles, L.
(1999) Ideals in intimate relationships. Journal of Personality and Social Psychology, 76, 72-89. doi:10.1037/0022-3514.76.1.72

[16] Fletcher, G.J.O., Simpson, J.A. and Thomas, G. (2000) Ideals, perceptions, and evaluations in early relationship development. Journal of Personality and Social Psychology, 79, 933-940. doi:10.1037/0022-3514.79.6.933

[17] Harris, K. (2011) Design features of add health. University of North Carolina, Chapel Hill.

[18] Harris, K. and Udry, J. (2008) National longitudinal study of adolescent health (add health), 1994-2008: Wave 1, public use data, data collection instrument and user guide. University of North Carolina, Chapel Hill.

[19] Mott, F.L. and Haurin, R.J. (1988) Linkages between sexual activity and alcohol and drug use among American adolescents. Family Planning Perspectives, 20, 128-136. doi:10.2307/2135701

[20] Bachmann, G., Bancroft, J., Braunstein, G., Burger, H., Davis, S., Dennerstein, L., et al. (2002) Female androgen insufficiency: The Princeton consensus statement on definition, classification, and assessment. Fertility and Sterility, 77, 660-665. doi:10.1016/S0015-0282(02)02969-2

[21] Stephanou, G. (2012) Romantic relationships in emerging adulthood: Perception-partner ideal discrepancies, attributions, and expectations. Psychology, 3.

[22] Overbeek, G., Ha, T., Scholte, R., de Kemp, R. and Engels, R.C.M.E. (2007) Brief report: Intimacy, passion, and commitment in romantic relationships-Validation of a "triangular love scale" for adolescents. Journal of Adolescence, 30, 523-528. doi:10.1016/j.adolescence.2006.12.002

[23] Collins, W. (2003) More than myth: The developmental significance of romantic relationships during adolescence. Journal of Research on Adolescence, 13, 1-24. doi:10.1111/1532-7795.1301001

[24] Collins, W.A., Welsh, D.P. and Furman, W. (2009) Adolescent romantic relationships. Annual Review of Psychology, 60, 631-652. doi:10.1146/annurev.psych.60.110707.163459

[25] Liang, W. and Chikritzhs, T. (2012) Brief report: Marital status and alcohol consumption behaviours. Journal of Substance Use, 17, 84-90. doi:10.3109/14659891.2010.538463

[26] Fleming, C.B., White, H.R. and Catalano, R.F. (2010) Romantic relationships and substance use in early adulthood. Journal of Health and Social Behavior, 51, 153167. doi:10.1177/0022146510368930 